\title{
CORRESPONDENCE
}

\section{A USE OF REFERENCE-POINTS IN STRATIGRAPHY}

SIR,- - Having recently come to the following conclusions in a discussion group here, we offer them for wider consideration and criticism as the present time promises opportunity, through discussion, of international decision.

1. The reference scale of periods/systems and ages/stages in current use in stratigraphy is no longer well enough defined to satisfy modern requirements including those of data storage and retrieval in geology. This is clear from the lack of agreement on procedure, and from the amount of effort now being put into the definition of boundaries.

2. Some attempts at definitions of boundaries appear to aim at refinements of the meanings of divisions (periods, ages) as if these divisions were natural. In common with many others, we see all such divisions as purely conceptual fragments of continuous geological history. The logical need for boundaries that are objective and stable has been expressed in the scheme for " markerpoints arbitrarily selected" (Geological Society Report-George et al., 1967, pp. 81-2, para. 3B). Although it is not explicit in the arrangement of their Report, we agree with the effect of the Geological Society SubCommittee's proposals to erect a Standard Stratigraphical Scale (p. 19, para. 3A) through the process of erecting such Regional Scales of points (p. 84, para. 4) as are necessary.

3. Reference-points in themselves have no characters except location in rock. They serve to divide rock sequences precisely (if arbitrarily) and so give a framework for reporting observations on rock or for any attempted timecorrelation between different sequences. This time-correlation is necessarily done by the interpretation of rock-characters from above and below the reference points.

4. Selected reference points can then be used as time-scale points to construct a standard stratigraphical scale (we prefer time-scale point to markerpoint). In applying reference points to a time scale, any (largely theoretical) difficulties of paraconformity and diagenesis in the section can be met by conceiving the point to be immediately beneath a suitable sediment-grain, with a time meaning of " immediately prior to the deposition of that sediment grain ".

5. We believe further that there could be advantages in providing primary names (preferable to, say, codes or accession numbers) for the time-scale points.

(a) This would enable secondary (combination) names to be used for the scale divisions between the time-scale points. Such a procedure would make it possible to refer directly with ease and brevity to the span between any pair of points on the time scale. It would also allow for either addition or disuse of time-scale points in a flexible way.

(b) The naming of points independently of divisions avoids dependence on any hierarchy such as at present obtains for divisions (eras, periods, ages). Although some hierarchy of terms is convenient for the human memory and for rapid communication at various levels of precision, it is not essential. We disagree, for instance, with the suggestion of SylvesterBradley (1967, p. 49, para. 2) that hierarchy and other details, which appear to be important in biological nomenclature, should be used in stratigraphy; we find minimum correspondence of aim between these two fields as at present conceived.

6. In recommending the use of reference-points (only some of which might be used as time-scale points) we are neither advocating the abandonment of traditional stratigraphical terminology nor opposing the use of points marking the beginnings/bases of stratigraphical divisions (Geological Society Report, p. 81, para. 3Biii). Our named reference-points could 
well be used in defining the beginnings/bases of divisions and in this event a dual system of names for divisions and for reference-points could exist.

7. The rock sequence in which any time-scale point could be usefully selected must have been first described by the best available methods of descriptive stratigraphy. We suggest therefore that the explicit use of reference-points (as defined in para. 3 above) should be encouraged in stratigraphical field records, and especially in measured sections. Later selection of some reference-points as time-scale points would then only be an extension of a normal working procedure.

8. We summarize the above in a recommended sequence of operations.

(i) Make general use of reference-points in descriptive stratigraphy for many purposes.

(ii) When time-correlation between strata is feasible, and it becomes useful to standardize a stratigraphical scale, suitable points would be selected and named for regional time-scale points either in individual publications or by the recommendation of regional or national committees.

(iii) Some of the above points would be selected by the Stratigraphical Commission of the I.U.G.S. as time-scale points in a (unique) Standard Stratigraphical Scale.

9. We believe it is vital for the future of our subject to improve stratigraphical practice. The insertion of a new nomenclature founded on named points could develop at a rate that would reflect convenience in usage. We are well aware of the general impracticability of revolutionary change in geological practice, and so advocate this permissive development. We do not claim originality, and indeed we hope to find that many colleagues already agree.

\section{REFERENCES}

George, T. N. et al., 1967. Report of the Stratigraphical Code Sub-Committee. Proc. geol. Soc. Lond., 1638, 75-87.

Sylvester-Bradley, P. C., 1967. Towards an International Code of Stratigraphical Nomenclature. In Essays in Paleontology and Stratigraphy (ed. C. TeICHERT and E. L. Yochelson), Spec. Publ. Dept. Geol. Univ. Kansas, 2, 49-56.

\section{DeParTMENT OF GEOLOGY, \\ SEdGWICK MUSEum, CAMBRIDGE.}

19th August, 1967.
N. F. Hughes.

D. B. Williams.

J. L. Cutbill.

W. B. HaRland. 